to the removal of one nail, but prefers the extraction of the other to be postponed to some future day. Accordingly, with the assistance of my friend and pupil, Mr. Grinfield Coxwell, I divided the matrix in its centre, and slightly loosened the horny structure from its attachments, when by a sudden avulsion it came away without any difficulty. She is doing well.

Woburn-place, April, 1866.

\section{ANSWERS TO INTERROGATORIES ON ENTERIC FEVER.}

BY W. ST. JOHN COLEMAN, L.C.P., L.R.C.S.I, MTDICAT OFFICBR OF THE MILTOWN MALBAY DISPENSARY DISTRICT, ETC.

Concedirs at once the desirability of " completing as far as possible our knowledge of the causation of fevers," I freely availed myself of the opportunities afforded me in an epidemic which visited my district during the past year in determining answers to THE LANCET interrogatories of Jan. 28th, 1865 . The substance of the following remarks is deduced from the treatment of nearly one hundred and fifty cases, and their accuracy is dependent on careful clinical notes taken at the time.

1. "On the importation of enteric fever by an infected person, or by fomites attached to clothes dc., into a locality where it has not been previously prevailing; and of its subsequent spread; with any facts relating to the mode of its propagation." On the 18th of April four cases of fever were brought under my notice. Three were of the gastric type, in the village; one enteric, some two miles distant in the country. To no source of contagion could any of them be attributed, but original sources of disease in each instance was rife. Ill-kept, faultilyconstructed sewerage, or heaped-up decaying vegetable and animal refuse matter in one or both.

2. "On the tendency to spread, or the reverse, of enteric fever in hospitals." The entire of my cases were treated in their own homes. With respect to its liability to spread, I quote from my report to the Poor-law Commissioners: "In every family where more than one member was attacked, the source of the disease was sure to be convenient, or the precautionary measures of cleanliness and removal of discharges neglected. In the cases where the poison was imbibed elsewhere than about their own premises, the disease never spread."

3. "Of the infecting power of the stools of persons suffering from enteric fever-apart from sewage." As in every instance I warned the attendants to destroy the stools, time sufficient was not allowed for the development of infection thereby, or, if so, only in such instances as left it impossible to discriminate between the sewage element and itself.

[After the foregoing was written in my note-book, $\mathrm{I}$ was brought to see the following case:-C. O. B-, aged fortynine, has had three children ill of fever; attended them throughout herself, and felt quite well until about a week ago, when, going down the lane from the house to empty "slops" in the river, she was detained by parties passing on the highway, from whom she screened herself in the ditch. During the period of concealment she experienced a most offensive odour from the vessel, which, to quote from herself, "sickened her heart," and necessitated her lying down. She took to her bed four days afterwards, and, fulfilling a presentiment which from that moment possessed her, died upon the fourteenth day from her exposure to the fetid emanation referred to.

4. "On the appearance of a single case of enteric fever in an isolated house, village, or other locality, independently of importation of the poison, stating particularly the degree of isolation, the reasons for excluding the possibility of importation, and the apparent cause of the fever." And,

5. "On the occurrence of a single case of enteric fever in family without anal subsequent spread." As many of the illustrations I deem it necessary to adduce are common to both these inquiries, it will, I trust, be permitted me to consider them together.

Mrs. H- upon the 23rd of April, and Sub-constable $\mathrm{M} \cdot \mathrm{M}$ - upon the same day, were prostrated by enteric fever. The former lives at the extreme end of the village from the parties alluded to as having been attacked on the 18th, and no communication could have taken place between them. Her husband and children, who occupied the cottage, and harl hourly access to her, escaped. In the instance of the policeman, he was exposed to no contagious influences whatever; but I learned afterwards that the privy was a favourite smolini place. "This man was permitted to share the same sleeping apartment with five others, not one of whom contracted the disease.

In continuation, I will quote briefly from my case-book.

Miss B - residing in a district peculiarly exempt from the fever, experienced a most offensive smell from some heapedup manure whilst out walking. She was obliged to sit down, so overpowering was it,she said; and eight days afterwards, when I saw her, twelve or fourteen lenticular spots showed themselves on the chest and abdomen, with diarrhoea of yellowish matter. Her sister was her constant attendant through out, and neither she nor the large household, between which and the patient she was a continually passing medium, were at any time then or afterwards infected.

M. C- - a labourer, aged twenty, was treated in the cabin shared by his mother, who attended him, his father, brothers, and sisters, every one of whom enjoyed an immunity from the disease.

B. C-, a labourer, occupying the same apartment with his parents, wife, and children, not one of whom suffered.

I select these, not that they were more remarkable examples, but because they come first of many similar cases; carefully studied clinical cases, that, as far as I myself am concerned, have placed beyond any doubt the non-communicability of typhoid or enteric fever, or its identity with typhus.

I propose to contribute a paper deduced from the study of the cases lately under my care; and although I can claim for it nothing but the care with which the notes upon which it is grounded were recorded, I cannot but hope that the importance of the diseased state, and the earnestness with which I studied it, may earn for my clinical observations the attention of my professional brethren.

Wavelands, 1866.

\section{LITHOTRITY SYRINGE.}

BY CHAS. FREDERICK MAUNDER, EsQ., F.R.C.S., SENIOR ASSISTAYT-SCRGEON TO THE LONDON MOSPITAX.

IN THE LANCET published on the 24th of February last I observed a reference to an instrument, invented by $\mathrm{Mr}$. Clover, for the withdrawal of fragments of calculus left in the bladder after the performance of lithotrity. At that time and now a patient was and is under my care with stone, who has the greatest difficulty, amounting almost to an impossibility, in voiding the smallest fragments; and $I$ was slowly removing the foreign body by means of the scooped lithotrite. I procured Mr. Clover's instrument, and found it to be of great service in removing débris; but, at the same time, was of opinion that the same principle of action might more advantageously be adapted to an instrument of a different shape. When using the syringe, I observed that the fragments of stone which passed into the glass receptacle of the instru. ment were, by the action of the india-rubber bottle, driven to and fro the bladder, instead of being permanently retained in the receptacle; also, as the water employed in the operation passed to and from the bladder, fragments of stone were heard rattling against the sides of the catheter, but were not always deposited in the receptacle. To facilitate the passage of calcareous mattor to the glass receptacle placed between the catheter and the bottle, and also to keep the fragments in the receptacle when once there, Ferguson, of Giltspur-street, has altered the instrument in two ways for me: 1st, the catheter is shorter by two inches; and 2nd, the old-fashioned smellingbottle shape of the glass portion of Mr. Clover's instrument is replaced by a glass receptacle very similar in form to a glass breast-pump. By these means the fragments of stone have a less distance to travel, and the depending portion of the apparatus plays the part of a trap, into which the pieces having gravitated, there is no possibility of escape therefrom. At present I have only used this instrument in a case in which the natural efforts are almost powerless to get rid of the débris ; but I believe the principle embodied in Mr. Clover's instrument will prove eminently useful in all cases of lithotrity. Small stones having been crushed, the fragments may be thus removed at one sitting; while, aided by clloroform, the number of sittings hitherto requisite for the destruction of a large calculus, and the length of time at present allowed between 
them for the spontaneous expulsion of débris, may be greatly diminished. The patient will be less liable to a laceration of, or lodgment of fragments of stone in, his urethra; and the train of disagreeable symptoms which sometines follow lithotrity need not be anticipated.

New Broad-street, April, 1866.

\section{d a dithror}

OF THE PRACTICE OF

\section{MEDICINE AND SURGERY IN THE}

HOSPITALS OE LONDON.

Nulla autem est alia pro certo noscendi via, nisi quamplurimas et morborum et dissectionum historias, tum aliorum, tum proprias collectas habere, et intor

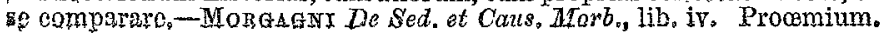

\section{MIDDLESEX HOSPITAL.}

NEW ORFRATION FOR THE RADICAL CURE OF NFVUS. (Under the care of Mr. NUNN.)

THF troublesome character of subcutaneous nævi situated on the foreheal, at the root of the nose, or near the brow, is well recognised; and a radical cure which shall leave no scar is certainly a desideratum. In subcutaneous nevi it is diffcult by ligature \&c. to make certain that the limits of the tumour are reached; and consequently an incomplete result is too frequently the only reward of a troublesome operation. In the treatment of the superficial cutaneous nævus, which is little more than what is called "port-wine stain," and in the "portwine stain" itself, pressure is of service. Mr. Nunn told us that Mr. Bigg, the surgical mechanician, had mentioned to him a case in which pressure by means of a light steel spring with a pad completely removed from the face of a young lady a very serious disfigurement of this kind. In the following instance a novel proceeding was adopted :-

C. M- male child, aged two years and a half, admitted July, 1865, with a circular nævus the size of a shilling situated on the right side of the forebead, over the frontal eminence. The tumour was more subcutaneous than cutaneous; the skin covering it had, however, been acted on by caustics \& c. before the patient carne under Mr. Nunn's charge, and the original appearance of the surface of the tumour was therefore no longer to be observed. Pressure by means of a cork pad and elastic band, as also the excitement of suppurative inflammation induced by setons, having failed to produce obliteration of the vessels constituting the nævus, Mr. Nunn made three incisions down to the bone (one horizontal and two vertical), so as to form a rectangular flap, which, when lifted up, included the tumour. The flap was so cut as to be reflected downwards. The dilated vessels forming the tumour were then clipped away as closely as possible to the cutis, which was very thin; the flap was replaced in its original position and secured by suture, moderate pressure being sur̂ncient to arrest bleeding.

Union by first intention was not quite complete; but on an inspection of the patient some months after the operation only a very faint line of cicatrix was visible, which will probably be barely perceptible in a few yoars.

\section{ST. BARTHOLOMEW'S HOSPITAL.}

POPLITEAL ANEURISM OF THE RIGHT LEG, IN A MAN WHO HAD PREVIOUSLY UNDERGONE THE OPERATION OF LIGATURE OF THE FEMORAL ARTERY FOR ANEUPISM IN THE OPPOSITE LIMB; LIGATURE OF THE RIGHT FEMORAL ARTERY; RECOVERY.

(Under the care of Mr. Hotmes Coote.)

IN a former case, now convalescent, operated on by $\mathrm{Mr}$. Coote, the aneurismal swelling was in Hunter's canal, and projected towards the inner part of the thigh. In the present sase, the tumonr was small and glohvlar, and situater hetween the hamstring tenctons. The patient, a spare man, thirty-two years of age, attributed the disease to the fact of his having walked from London to Manchester in search of work. The first operation was done at Liverpool, and with complete suc. cess. The second was performed at St. Bartholomew's Hospital, on the 14th of April, by Mr. Coote. An incision having been made down to the inner border of the sartorius, that muscle was pulled gcntly aside; the sheath of the artery was then opened, and the neodle passed round the vessel, care being taken to displace the parts as little as possible. The tying of the ligature was followed by the complete cessation of pulsa. tion in the aneurismal sac, nor has there been any return of pulsation in the least degree.

The patient had not experienced much inconvenience from the presence of the aneurism; and Mr. Coote remarked that the circulation was undisturbed below the swelling, and there was an absence of the usual feeling of numbness in the limb. These circumstances were explained by the fact of the aneurism being small, and of such a nature as not to interfere with the current of blood.

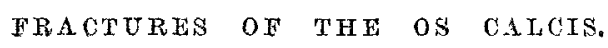

(Under the care of Mr. Coone.)

Fractures of the os calcis proceed either from muscular action or from direct violence. Of the former we saw an instance in Stanley ward, under Mr. Coote's care, in the person of a middle-aged woman, who slipped down a stone step on leaving a house. She walked some distance afterwards to her house, and thence to a railway station, before coming to the hospital. The muscles of the calf had pulled the upper fragment away to the extent of two or three inches, and turned it on itself, so that the broken edge looked backwards. She was kept in bed, and the foot pointed downwards by the aid of a padded turned splint. By degrees the upper fragment came nearer to the lower, and good fibrous union was established, when the patient, by her own desire, left the hospital.

An instance of fracture from direct violence is now in Rahere ward, also under the care of $\mathrm{Mr}$. Coote. A Welsh milkman, sixty-four years of age, was knocked down by a cab, the wheel of which passed over his heel. In this case the tendo-Achillis was completely divided, and projected from a lacerated wound of the integument; the os calcis was broken into many frag ments. The patient could not bear any mechanical appliance, consequently a charcoal poultice only was applied, the tendon having been replaced. A considerable amount of sloughing ensued, but no unfavourable symptom supervened. The wound is now granulating healthily, and the deep-seated flexor muscles have sufficient power to keep the foot at right angles to the leg.

\section{LONDON HOSPITAL.}

PAINFUL IN-GROWING NAILS OF GREAT TOES OF BOTH FEET, OURED BY OPERATION WITHOUT INTEREERENOE WITH THE NAILS.

(Under the care of Mr. CURIING.)

THE following notes were furnished us by Mr. F. S. Colqu. houn :-

Henry W-, aged eighteen years, was admitted on Nor. 30th, 1865, suffering from in-growing of the nails of the great toes of both feet. The ends of both toes presented a bulbons enlargement, the outer edge of the nails being buried deeply in the mass. He stated that he had been subject to it for tho last twelve months, and attributed it to his cutting the nails short and rounding the corners. They gave him great pain and inconvenience. He had walked lame for six months, and had been obliged to cut his boots so as to enable him to wear them at all; but for the last four months he had been able to wear only slippers.

On Dec. 7th, Mr. Curling excised, under chloroform, the whole of the bulbiform enlargement close up to the outer edge of the nail. This portion, which was about the size of a large nut, was cut so that a sloping surface directed towards the midale line of the toe was left; thus the in-growing nail was completely exposed, and overhanging the raw surface. Mr. Curling explained at the time that when the surface healed, the cicatrix would contract, and so make the nail overhang more, and thus complete the cure. Wet lint was applied to the toes throughout, the wounds healed rapidly, and a fort. night after the operation the lad left the hospital, able to walk, 